\title{
Activation of Toll-Like Receptors and Inflammasome Complexes in the Diabetic Cardiomyopathy-Associated Inflammation
}

\author{
J. Fuentes-Antrás, ${ }^{1}$ A. M. Ioan, ${ }^{1}$ J. Tuñón, ${ }^{1}{ }^{J}$. Egido, ${ }^{1,2}$ and Ó. Lorenzo ${ }^{1,2}$ \\ ${ }^{1}$ Cardiovascular Research Laboratory, IIS-Fundación Jiménez Díaz, Autónoma University, Avenida Reyes Católicos 2, \\ 28040 Madrid, Spain \\ ${ }^{2}$ Spanish Biomedical Research Centre in Diabetes and Associated Metabolic Disorders (CIBERDEM) Network, \\ Avenida Reyes Católicos 2, 28040 Madrid, Spain
}

Correspondence should be addressed to Ó. Lorenzo; olorenzo@fjd.es

Received 25 November 2013; Accepted 23 January 2014; Published 12 March 2014

Academic Editor: Ajit Vikram

Copyright (C) 2014 J. Fuentes-Antrás et al. This is an open access article distributed under the Creative Commons Attribution License, which permits unrestricted use, distribution, and reproduction in any medium, provided the original work is properly cited.

\begin{abstract}
Diabetic cardiomyopathy is defined as a ventricular dysfunction initiated by alterations in cardiac energy substrates in the absence of coronary artery disease and hypertension. Hyperglycemia, hyperlipidemia, and insulin resistance are major inducers of the chronic low-grade inflammatory state that characterizes the diabetic heart. Cardiac Toll-like receptors and inflammasome complexes may be key inducers for inflammation probably through NF- $\kappa$ B activation and ROS overproduction. However, metabolic dysregulated factors such as peroxisome proliferator-activated receptors and sirtuins may serve as therapeutic targets to control this response by mitigating both Toll-like receptors and inflammasome signaling.
\end{abstract}

\section{Introduction}

Cardiac complications are the leading cause of morbidity and mortality in diabetic patients [1]. First introduced by Rubler et al. in 1971 [2], diabetic cardiomyopathy (DCM) is characterized by the direct effect of diabetes on cardiac structure and function in the absence of coronary artery disease, hypertension, or other cardiac pathologies. DCM entails the damage of the myocardium through fibrosis, steatosis, apoptosis, and hypertrophy [3] and results from the switch of substrate supply to free fatty acids (FFA) that follows the reduced levels of insulin, glucose transporters, and glucose consumption $[4,5]$. Subsequent disruption of calcium homeostasis and myocardial remodeling leads to a progressive impairment of ventricular myocyte contractility that may result in heart failure [6-8]. In addition, an increasing body of evidence suggests a potential link between oxidative energy metabolism dysregulation and chronic lowgrade inflammation $[4,9]$.

Inflammatory signaling in cardiomyocytes usually occurs as an early response to myocardial injury and entails cytosolic and mainly mitochondrial reactive oxygen species (ROS) overproduction [10, 11]. Classical following steps mainly involve increased activation of the proinflammatory nuclear transcription factor- $\kappa \mathrm{B}(\mathrm{NF}-\kappa \mathrm{B})$, and the related expression of cytokines (i.e., tumour necrosis factor- $\alpha$ (TNF $\alpha)$, interleukins (IL-1 $\beta$, IL-6), and chemokines (i.e., MCP-1)), adhesion molecules (i.e., selectins and adhesion molecules (ICAM-1, VCAM-1)), and successive migration of leukocytes into the myocardium [12, 13]. Migrated monocytes can further develop into tissue macrophages, which can then be polarized into two main groups, M1 and M2, accounting for their trend towards inflammation or healing, respectively. We and others have reported that myocardial inflammation develops in human patients and experimental models of type 1 (T1DM) and type 2 (T2DM) diabetes mellitus $[8,14,15]$. There is evidence that chronic progression of hypertrophy, fibrosis, and ventricular dysfunction is correlated with a local increase in cytokines [16] and activation of NF- $\kappa \mathrm{B}[17,18]$. General inflammatory stimuli in the diabetic heart include hyperglycaemia, hyperlipidemia, ROS, angiotensin II, and endothelin-1 $[4,19]$. Activation of Toll-like receptors (TLRs) 
and the inflammasome complex has recently been proposed to be central in cardiac inflammation and likely in the pathogenesis of DCM.

\section{Toll-Like Receptors and Cardiac Inflammation}

TLRs are membrane-anchored proteins present in several cell types ranging from macrophages and $\mathrm{T}$ and $\mathrm{B}$ cells to nonimmune cells such as cardiomyocytes [20, 21]. They work as pattern recognition receptors (PRRs) implicated in tailoring innate immune signaling [22]. TLRs elicit conserved inflammatory pathways culminating in the activation of NF$\kappa \mathrm{B}$ and activating protein-1 (AP-1). TLR ligands include highmobility group B1 (HMGB1), heat shock proteins (HSP60, HSP70), endotoxins, and extracellular matrix components [23]. Also ROS can modify membrane components and cause the release of factors that interact with and activate TLRs. In this sense, it has been shown that TLR2 participated importantly in the mechanism of ROS-induced activation of NF- $\kappa \mathrm{B}$ and AP-1 [24]. The proximal events of TLRmediated intracellular signaling are initiated by interactions with cytosolic adapters, mainly myeloid differentiation primary response protein 88 (MyD88) [25]. MyD88 recruits the IL-1R-associated kinase (IRAK) and TNFR-associated factor (TRAF) to induce ubiquitination and proteasomal degradation of the inhibitors of NF- $\kappa \mathrm{B}$ (I $\kappa \mathrm{Bs})$, thus enabling NF- $\kappa \mathrm{B}$ translocation into the nuclei and further ROS generation [25] (Figure 1(a)). The isoforms predominantly expressed in cardiomyocytes are TLR2 and TLR4, although up to ten cardiac TLR mRNAs have been identified in several clinical contexts including obesity and T2DM [26-29]. TLR2 and TLR4 have a central role in the pathogenesis of diverse heart disorders. Both are strongly upregulated in chronic dilated cardiomyopathy and heart failure [30], serving as upstream inducers of a large variety of proinflammatory molecules including ICAM-1, chemokines, TNF $\alpha$, interleukins, HSPs, interferon$\gamma(\operatorname{IFN} \gamma)$, and inducible nitric oxide synthase (iNOS) [21, 28, 31]. Activation of TLR2 and TLR4 eventually leads to reduction of ejection fraction through NF- $\kappa \mathrm{B}$-dependent mechanisms [31, 32]. However, the specific distinction of the mechanisms and targets between TLR2 and TLR4 in cardiac inflammation is a rapidly evolving knowledge that presents some divergence. Boyd et al. reported that stimulation of TLR2 and TLR4 in HL-1 cardiomyocytes decreased contractility and initiated NF- $\kappa \mathrm{B}$-dependent inflammatory response, involving upregulation of ICAM-1, chemokines, and macrophage inflammatory protein-2 (MIP-2). However, only TLR4 activation induced the proinflammatory cytokine IL-6 [31]. More recently, Ma et al. [30] uncovered the differential effects of TLR2 and TLR4 in a doxorubicininduced mice model of chronic dilated cardiomyopathy. TLR2 blockade reduced myocardial expression of a variety of proinflammatory factors including IFN $\gamma$ and MCP-1. Conversely, TLR4 blockade increased secretion of MCP-1, IL-13, and transforming growth factor- $\beta_{1}\left(\mathrm{TGF} \beta_{1}\right)$. Besides structural cardiomyopathies, TLR2 and TLR4 have progressively gained credit as important contributors to entities of metabolic nature such as cardiac lipotoxicity. In this line, TLR4 knockdown abrogated NF- $\kappa$ B-dependent inflammatory response and lowered insulin resistance in high-fat fed mice [33].

2.1. Activation of TLRs in DCM. Several studies have addressed the role of TLRs in cardiac inflammation using models of T1DM, T2DM, and obesity, which share an environment characterized by high circulating levels of glucose and FFA and elevated tissue levels of ceramides. Although no direct interaction between glucose and FFA with TLRs has been described [34], high levels of glucose and lipids have been shown to stimulate TLR2 and TLR4 [33, 35, 36 , thus suggesting the existence of unknown intermediates. High-fat diet-induced obese mice exhibited myocardial macrophage infiltration as well as higher expression levels of TLR4, MyD88, and IL-6 [37]. Consistent with this, both diabetic TLR2 and TLR4-deficient mouse hearts showed lower triglyceride accumulation during the early stages of diabetes, as well as restricted leukocyte infiltration and a marked decrease of NF- $\kappa \mathrm{B}$ and MyD88 and phosphorylation of IRAK1 [20, 38]. Different studies in T1DM mice models show that TLR4 silencing prevents cardiac lipid accumulation, hyperglycemia-induced myocardial apoptosis, and ventricular remodeling and dysfunction. It also suppresses the diabetic upregulation of NADPH oxidase activity and thus ROS production [20,39]. Furthermore, genetic analysis of patients has pointed an association between TLR4 polymorphisms, diabetes prevalence, and the severity of chronic cardiomyopathy $[40,41]$. However, besides the focus on the alterations of cardiomyocytes, leukocyte activation and transmigration into the diabetic myocardium constitute a pivotal process in the inflammatory response. Hyperglycemia has been shown to upregulate TLR2, TLR4, MyD88, and IRAK-1 phosphorylation and TLR-mediated transactivation of NF- $\kappa \mathrm{B}$ in human monocytes from T2DM patients [28, 42]. Concurrently, TLR2 increased in mononuclear cells from long-standing T1DM patients [43]. In macrophages from a model of nonobese T2DM mice, Mohammad et al. described a ten-fold increase of TLR4 and higher levels of cytokines, while anti-inflammatory IL-10 was downregulated [21]. Consistent with this view, monocytes from T2DM patients also exhibited significant increment in proinflammatory cytokines and TLR2 and TLR4 ligands (HMGB1 and HSPs) [28]. Similar to what occurred in cardiomyocytes, siRNA knockdown of TLR2 and TLR4 led to decreased NF$\kappa \mathrm{B}$ activity and IL- $1 \beta$ release in monocytes [42]. Therefore, it seems that TLRs may be activated in both cardiomyocytes and leukocytes, in DCM-associated cardiac inflammation ten-fold.

\section{Inflammasomes and Cardiac Inflammation}

The inflammasome is a group of multimeric protein complexes composed of a cytoplasmic receptor of the NodLike Receptor (NLR) family, an adaptor protein termed ASC (Apoptosis-associated Speck-like protein containing an $\mathrm{N}$-terminal caspase recruitment domain CARD), and 
procaspase-1 [44]. The best characterized complex is the NLRP3 inflammasome, which has been identified in a wide range of cells including macrophages, cardiofibroblasts, and cardiomyocytes [45-48]. NLRP3 has been reported to be held in an inactive state by cytoplasmic chaperones. Once NLRP3 is freed, subsequent oligomerization leads to the recruitment of procaspase-1, thus promoting autocleavage and activation [44]. Active caspase- 1 can eventually process IL- $1 \beta$ and IL-18 precursors, serving as enhancer of multiple proinflammatory pathways including NF- $\kappa \mathrm{B}$, mitogen-activated protein kinase (MAPK), IFN $\gamma$, chemokines, and ROS and also promoting insulin resistance [49] (Figure 1(b)). NLRP3 can be activated by long-chain saturated FA (i.e., palmitate), ceramides, modified LDL, and hyperglycemia [50-52]. However, NLRP3 does not have a known direct ligand and it requires twocheckpoint activation process including a priming step and a second activation step [53]. NF- $\kappa \mathrm{B}$ is the traditional priming signal for the transcription of the NLRP3 gene [54], whereas novel mechanisms have recently emerged as a second step. These are based on posttranslational activation of NLRP3 by deubiquitination [55], oxidized mitochondrial DNA [56], and potential ligands such us thioredoxin-interacting protein (TXNIP) [57]. In addition, a recent study by Bauernfeind et al. has revealed that NLRP3 expression is critically regulated by myeloid specific microRNA-223 [58]. Nevertheless, to date, most data about NLRP3-inflammasome implication in heart disease and inflammation come from murine models of ischemic damage and dilated cardiomyopathy [48, 59, 60]. In a model of dilated cardiomyopathy, NLRP3 ablation was related to a general reduction in proinflammatory cytokines maturation, reduced mononuclear infiltrate, maintained myocyte organization and structure, and preserved systolic performance [48]. In addition, these hearts increased phosphorylation of $\mathrm{I} \kappa \mathrm{B} \alpha$, what is consistent with NF- $\kappa \mathrm{B}$ regulated NLRP3 gene expression. Further evidence shows upregulation of the NLRP3-inflammasome effector caspase-1 in murine and human myocardial infarction [61]. In this study, deletion of endogenous caspase-1 consistently ameliorated the ventricular function of the postinfarcted heart. However, many aspects are in need of further clarification. NLRP3 mRNA levels have been found to be markedly diminished in heart samples from the right atrium of patients undergoing coronary bypass surgery [60]. Moreover, Zuurbier et al. have recently reported that deletion of NLRP3 resulted in decreased myocardial IL-18 and IL- 6 levels, but this effect was not observed for IL- $1 \beta$ and TNF $\alpha$ levels. Also, deletion of the ASC component did not downregulate IL-6, IL- $1 \beta$, or TNF $\alpha$ [59]. Despite this, gene polymorphisms and mutations in the human NLRP3-inflammasome have been shown to be associated with an increase of IL-1 $\beta$ and IL-18, higher levels of C-reactive protein (CRP), and severe inflammation [62-64].

3.1. Activation of NLRP3-Inflammasomes in DCM. Not much research has been done to assess the plausible implication of inflammasomes in experimental models of DCM. However, as for TLRs, several recent studies have emphasized that NLRP3 inflammasomes might represent the link between inflammation and metabolic disorders such in the diabetic heart. It is known that NLRP3 signaling affects glycolysis and insulin sensitivity and simultaneously enhances both local myocardial cytokine levels and infiltration by macrophages [51, 65]. Recent data also suggest that NLRP3 is responsible for sensing obesity-associated host-derived inducers of caspase-1, such as ROS and lipotoxic ceramides and palmitate [66]. In fact, NLRP3 inflammasomes have been proposed to sense and mediate downstream inflammatory events of glycotoxicity and lipotoxicity during the pathogenesis of T2DM $[45,57]$. Cardiac NLRP3, caspase1 , and IL- $1 \beta$ expression was substantially increased in obese mice and human subjects [45]. Moreover, caloric restriction and exercise-mediated weight loss in obese individuals with T2DM were shown to effectively reduce the expression levels of NLRP3 [67]. In contrast to the scarce contributions in cardiomyocytes, research on NLRP3 inflammasomes has intensively focused on inflammatory cells. NLRP3 has been reported to increase effector $\mathrm{T}$-cell number, thus eliciting macrophage transmigration. Further, NLRP3 upregulates the pool of proinflammatory cytokines such as IL-1 $\beta$, IL-18, and IFN $\gamma$ and promotes insulin resistance in $\mathrm{M} 1$ macrophages [45]. In addition, both ceramides and palmitate require an intact NLRP3 signaling to induce caspase- 1 activation and IL$1 \beta$ and IL-18 release from macrophages $[45,66]$. Thus, NLRP3 inflammasome may also participate in the cardiomyocyte and monocyte response in DCM-associated inflammation.

\section{Potential Crosstalk between TLRs, Inflammasomes, and Metabolic Dysregulation in DCM}

Interestingly, TLR2 and TLR4-mediated ROS generation and NF- $\kappa$ B transactivation upregulate NLRP3 pathway through multiple direct and indirect mechanisms, which account for both NLRP3 priming and the secondary steps of activation (Figure 2). First, ROS/NF- $\kappa \mathrm{B}$ has been reported to enhance the expression of NLRP3 and caspase-1 target pro-IL-1 $\beta$, and $\mathrm{NF}-\kappa \mathrm{B}$ sites in NLRP3 promoter have been identified [36, $54,67]$. Second, ROS/NF- $\kappa$ B facilitates NLR posttranslational deubiquitination [55]. And third, ROS/NF- $\kappa \mathrm{B}$ increases the amount of TXNIP and oxidized mitochondrial DNA, which might serve as ligands of NLRP3 [56, 57]. Thus, NLRP inflammasome activation is likely to be a key outcome of TLR stimulation in DCM. Moreover, another connection between TLRs and inflammasomes may be through metabolic dysregulated factors, such as peroxisome proliferator-activated receptors (PPARs) and sirtuins (Sirts) (Figure 2). Activation of PPARs is a key process in the myocardial switch of substrates in DCM and has recently emerged as a link between metabolism disturbance and pathological inflammatory/oxidative phenomena [68]. The PPAR transcription factor family is extensively known to regulate cardiac metabolism, mainly through $\operatorname{PPAR} \alpha$ and $\operatorname{PPAR} \beta / \delta$ isoforms together with PGC- $1 \alpha$ coactivator [69]. PPAR $\alpha / \mathrm{PGC}-1 \alpha$ leads to transcriptional induction of pyruvate dehydrogenase kinase-4 (PDK4), FAT/CD36 transporter, and FFA oxidation enzymes [70], thereby facilitating mitochondrial FFA import and $\beta$-oxidation-dependent metabolism in expenses 
of glucose assimilation. Thus, NF- $\kappa \mathrm{B}$ and p38-mediated PPAR $\alpha /$ PGC- $1 \alpha$ inhibition has been described as an important pathological mechanism in DCM progression [71]. In addition, a wide body of evidence indicates that PPARs mitigate inflammation. PPARs lower nuclear factor of activated Tcells (NFAT) signaling and prevent the expression of NADPH oxidase subunits, resulting in ROS amelioration [72, 73]. PPARs also downregulate TLR2 and TLR4 signaling by either blocking TLR expression or its NF- $\kappa \mathrm{B}$ and AP-1-dependent pathways [74-76]. The effects on NF- $\kappa \mathrm{B}$ seem to be mediated through direct physical interactions, sequestration of NF$\kappa \mathrm{B}$ coactivators, and transcriptional control of NF- $\kappa \mathrm{B}$-related proinflammatory genes [77-79]. Other DNA-independent mechanisms to inhibit NF- $\kappa \mathrm{B}$ include activation of ERKMAPK pathway, mainly by impairing phosphorylation of factors such as p38- and JNK-MAPK [4]. Notably, these are also targets of TLR-Myd88/IRAK signaling in the heart $[18,80]$. Further direct evidence from obese T2DM mice has demonstrated that PPAR $\beta / \delta$ and PPAR $\gamma$ downregulate both TLR 2 and TLR 4 signaling $[75,81]$. Moreover, TNF $\alpha$ and IL-1 $\beta$ have been reported to be clearly decreased upon activation of $\operatorname{PPAR} \alpha[82,83]$, which can be linked with impaired NF- $\kappa \mathrm{B}-$ dependent induction of NLRP3 inflammasome. In a model of chronic high-fructose-induced diabetic mice, Collino et al. described that PPAR $\beta / \delta$ stimulation attenuated NLRP3dependent caspase-1 activation and IL-1 $\beta$ production [74]. Also, the NLR family promoter harbours binding sites for $\operatorname{PPAR} \gamma$ [84]. More complex evidence regards the interference of the inflammasome assembly by phospholipase $\mathrm{C}$, cyclic AMP, and protein kinase $\mathrm{C}$, which are known regulators and targets of PPARs [85-87].

In addition to PPARs, Sirts may constitute another alleged nodal connection between metabolism and TLR and/or inflammasome-dependent inflammation [88] (Figure 2). Moreover, Sirts have been largely reported to interfere with the molecular pathogenic substrate of heart failure and thereby ameliorate cardiac outcome [89]. Epigenetic modulation by this class III deacetylase limits oxidative stress and inflammatory responses by targeting a relevant set of transcription factors including NF- $\kappa$ B, PPARs, and PGC- $1 \alpha$ [90]. Sirtuin-1 (Sirt1), the most studied Sirt in the heart, works as an energy sensor and supports oxidative energy metabolism through PPAR $\alpha /$ PGC- $1 \alpha$ and AMPactivated protein kinase (AMPK) signaling, which also contribute to inhibit NF- $\kappa \mathrm{B}$ and inflammation [91]. Mice overexpressing Sirtl and exposed to high-fat diet show attenuated lipid-induced inflammatory responses [92]. Also, Sirtl was reported to stimulate antioxidants manganese superoxide dismutase (MnSOD) and nuclear respiratory factor-1 (Nrfl) in the heart, downregulating NF- $\kappa \mathrm{B}$ targets TNF $\alpha$ and IL-6 [93]. Several mechanisms for the modulation of NF- $\kappa$ B signaling by Sirtl have been described. First, Sirtl has been associated with PPAR $\alpha$-dependent inhibition of p65 subunit of NF- $\kappa$ B [94]. Second, Sirtl may directly modulate NF- $\kappa \mathrm{B}$-dependent immune responses and coupled ROS production by deacetylating p65 [95]. And third, Sirtl can negatively regulate the expression of TNF $\alpha$ and IL- $1 \beta$ by binding to specific sites in their promoters [96]. Further connections between Sirtl, TLRs and inflammasomes include Sirtl downregulation by palmitate-induced miR-195 and Sirtl cleavage by caspase-1 [92, 97]. Taken together, activation of both PPARs and Sirtl may control the TLR and inflammasome-dependent pathways of inflammation in DCM, which may be useful for a therapeutic target.

\section{Prospective Therapeutic Targets for DCM}

Despite the prolific area of research linking inflammation, diabetes and metabolic heart disease, the drugs currently employed in the care of diabetic patients have not generally been based on an anti-inflammatory strategy. Pharmacological modulation of TLRs undoubtedly arises as a highly attractive therapeutic strategy for DCM. In this regard, several TLR antagonists have been assessed in diverse models of myocardial contractile dysfunction. Selective inhibition of TLR2 by immunoglobulin G (IgG) has been successfully attempted to ameliorate $\mathrm{NF}-\kappa \mathrm{B}$ and leukocyte infiltration in ischemic murine hearts [98]. TLR4 antagonists, eritoran, and geldanamycin resulted in attenuated myocardial inflammatory responses including reduced $\mathrm{p}$-JNK and NF$\kappa \mathrm{B}$ nuclear translocation and decreased gene transcripts of TNF $\alpha$, IL- $1 \beta$, IL-6, MCP-1, MIP- $1 \alpha$, and MIP-2 $[99,100]$. These data underscore the potential benefit of blocking TLR signaling for DCM. However, an increasing number of TLR inhibitors are not being proportionally tracked by studies measuring their impact in animal models of cardiac disease [101, 102]. The discovery of novel mechanisms for common drugs also paves the way for potential therapeutic strategies. For example, statins attenuated the upregulation of TLR4 and TLR2, inhibited NF- $\kappa \mathrm{B}$, and decreased the circulating levels of TNF $\alpha$, MCP-1, and CRP in a mice model of dilated cardiomyopathy $[103,104]$. Also, angiotensin II receptor blocker valsartan decreased TLR4-mediated NF- $\kappa \mathrm{B}$ activity and subsequent cytokine release in a rat model of ischemic heart [105]. In addition, cumulative evidence on $\mathrm{NF}-\kappa \mathrm{B}$ and TNF $\alpha$ targeting suggests the therapeutic value of specific modulation of TLR downstream effectors. Triptolide, a potent NF- $\kappa$ B immunomodulator and TNF $\alpha$ monoclonal antibody treatment significantly decreased TNF $\alpha$, IL- $1 \beta$, ICAM-1, VCAM-1, and subsequent myocardial infiltration by macrophages and T-cells in diabetic hearts $[106,107]$.

No NLR antagonist has been identified yet, and increasing efforts are being invested as a result of successful blockade of downstream effectors IL- $1 \beta$ and caspase- 1 in DCM. Very recent evidence reported that intravenous IgG therapy protected neurons in an experimental model of stroke through a mechanism involving suppression of the NLRP3 inflammasome activity [108]. Moreover, the antiIL-1 $\beta$ Anakinra [109] and Gevokizumab [110] clinical trials resulted in reduced TNF $\alpha$, IL-6, IL- $1 \beta$, and CRP. However, despite reducing biomarkers of heart disease, they did not restore hyperglycemia. Nonimmune antagonists of the inflammasome machinery are equally compelling. Pralnacasan, a caspase-1 blocker, has been reported to attenuate inflammation in a model of DCM by reducing IL- $1 \beta$, IL$18, \mathrm{TNF} \alpha$, and IFN $\gamma$ levels, intracardiac macrophage, and lymphocyte infiltrates and also to improve insulin sensitivity 


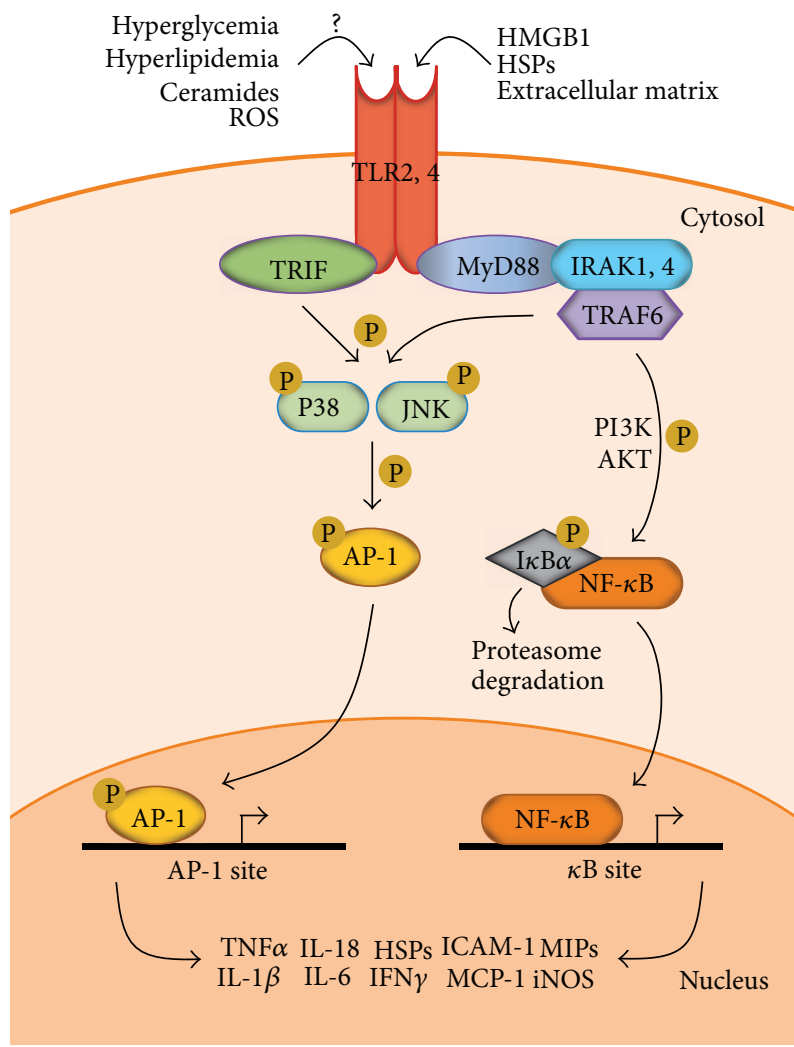

(a)

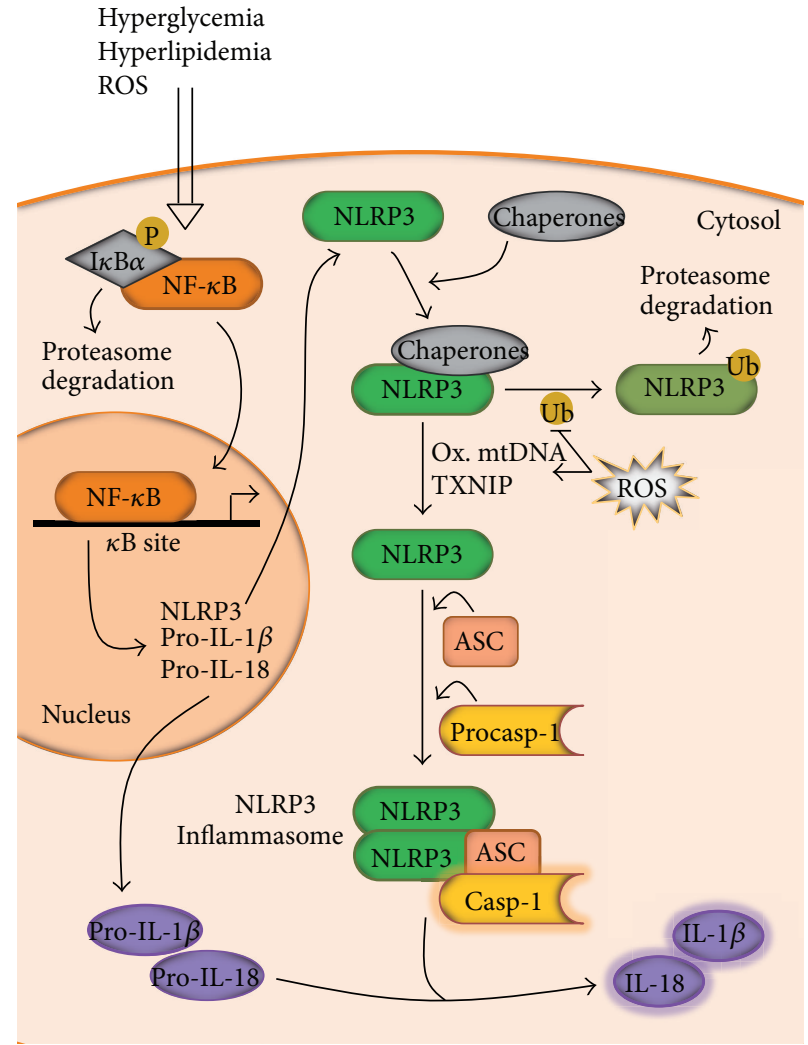

(b)

FIGURE 1: TLRs and NLRP3 inflammasome activation in the proinflammatory myocardium. (a) Activation of TLR2 and TLR4, (b) and NLRP3 inflammasome complexes in cardiomyocytes.

$[107,111]$. Novel anti-inflammasome properties have been described for classical antidiabetics such as metformin and sulfonylurea. Metformin may affect NLRP3 signaling by enhancing autophagy through AMPK $[66,112]$ or increasing Sirtl action [113, 114]. In this line, AICAR, an AMPK agonist, could also restore the formation of autophagosomes and thereby inhibit both caspase- 1 and ROS generation in palmitate-treated macrophages [66]. Sulfonylurea glyburide also suppressed the NLRP3-dependent caspase-1 activation and IL-1 $\beta$ release [115]. Finally, Jourdan et al. showed that the blockade of cannabinoid receptor type 1 (CB1R) lowered the levels of NLRP3, ASC, IL-1 $\beta$, IL-18, NF- $\kappa$ B, and caspase-1 in macrophages from ZDF rats [116].

Beyond the regulation of TLRs and inflammasomes, therapeutic benefit of PPARs and Sirtl stimulation on T2DM and its cardiac complications has been reported in recent years [117-120]. Interestingly, a PPAR $\alpha$ agonist, fenofibrate, decreased TLR4 and MyD88 expression in a model of multiple sclerosis [121]. PPAR $\gamma$ agonist pioglitazone substantially inhibited the expression of TLR2, TLR4, MyD88, and NF$\kappa \mathrm{B}$ in macrophages from obese T2DM mice [75]. Moreover, PPAR $\beta / \delta$ agonist GW0742 impaired NLRP3 inflammasome activity in high-fructose diet-induced diabetic mice [74]. Since TLR4 downregulation was identified as an antiinflammatory mechanism of the insulin-sensitizer incretin glucagon-like peptide-1 (GLP-1) [122], and considering that a PPAR $\beta / \delta$ agonist markedly upregulated GLP-1 in obese T2DM mice [123], it is possible that $\mathrm{PPAR} \beta / \delta$ stimulation may be a valid therapeutic tool for DCM. In the same way, a bulk of emerging evidence has identified Sirts as a future therapeutic target for diabetic complications. In this sense, small molecule activators of Sirtl are currently being developed. ZDF rats undergoing this treatment effectively improved whole-body glucose homeostasis and insulin resistance [124]. However, no attempt to measure the impact of Sirtl enhancement in DCM has been made.

\section{Conclusions}

TLRs and the inflammasome signaling platforms could be two main breakthroughs on cardiac inflammation. Emerging evidence supports a model in which hyperglycemia and FFA stimulate TLRs as upstream inducers of proinflammatory mechanisms in DCM. TLR-dependent NF- $\kappa$ B and ROS appear to regulate both the priming and posttranslational steps required for the assembly and activation of the inflammasome. However, metabolic dysregulated factors such as PPARs and Sirtl can downmodulate DCM inflammation by interfering with TLRs and inflammasome signaling. Thus, a new set of potential therapeutic approaches for DCM may 


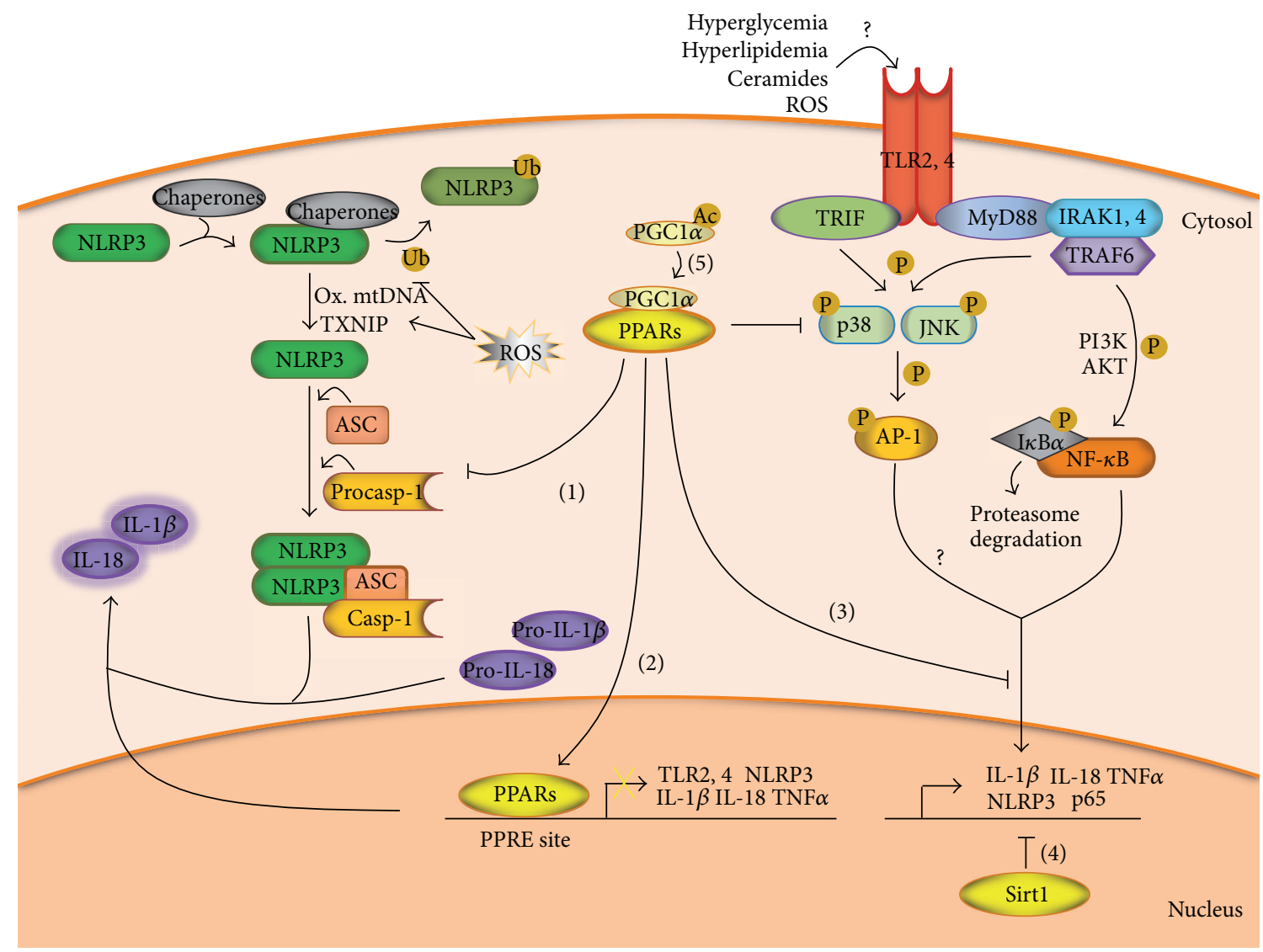

FIGURE 2: Crosstalk between TLRs, NLRP3 inflammasomes and dysregulated metabolic factors in DCM. PPARs and Sirt1 may control NLRP3 inflammasome and TLR pathways by interfering with the inflammasome assembly (1), proinflammatory gene overexpression (2), and NF- $\kappa \mathrm{B}$ signaling (3-4). In addition, Sirtl could mediate PPARs activation by PGCl $\alpha$ deacetylation (5).

include the stimulation of PPARs and Sirtl and the inhibition of TLR2, TLR4, and NLRP3. Further, targeting proximal TLR mediators Myd88 and IRAK and the activation steps of the inflammasome may yield some clinical benefit in DCM.

\section{Conflict of Interests}

The authors declare that there is no conflict of interests.

\section{Acknowledgments}

This work was supported by National Grants from Ministerio de Educación y Ciencia (SAF2009-08367), Comunidad de Madrid (CCG10-UAM/BIO-5289), and FISS (PI10/00072).

\section{References}

[1] S. Boudina and E. D. Abel, "Diabetic cardiomyopathy revisited," Circulation, vol. 115, no. 25, pp. 3213-3223, 2007.

[2] S. Rubler, J. Dlugash, Y. Z. Yuceoglu, T. Kumral, A. W. Branwood, and A. Grishman, "New type of cardiomyopathy associated with diabetic glomerulosclerosis," The American Journal of Cardiology, vol. 30, no. 6, pp. 595-602, 1972.
[3] Y. F. Zhi, J. B. Prins, and T. H. Marwick, "Diabetic cardiomyopathy: evidence, mechanisms, and therapeutic implications," Endocrine Reviews, vol. 25, no. 4, pp. 543-567, 2004.

[4] X. Palomer, L. Salvado, E. Barroso et al., "An overview of the crosstalk between inflammatory processes and metabolic dysregulation during diabetic cardiomyopathy," International Journal of Cardiology, vol. 168, no. 4, pp. 3160-3172, 2013.

[5] H. Taegtmeyer, P. McNulty, and M. E. Young, "Adaptation and maladaptation of the heart in diabetes-part I: general concepts," Circulation, vol. 105, no. 14, pp. 1727-1733, 2002.

[6] I. Shiojima and I. Komuro, "Molecular mechanisms of congestive heart failure," Nippon Rinsho, vol. 64, no. 5, pp. 826-831, 2006.

[7] W. B. Kannel, M. Hjortland, and W. P. Castelli, "Role of diabetes in congestive heart failure: The Framingham Study," American Journal of Cardiology, vol. 34, no. 1, pp. 29-34, 1974.

[8] D. Westermann, S. Rutschow, S. Jäger et al., "Contributions of inflammation and cardiac matrix metalloproteinase activity to cardiac failure in diabetic cardiomyopathy: the role of angiotensin type 1 receptor antagonism," Diabetes, vol. 56, no. 3, pp. 641-646, 2007.

[9] E. Ramírez, M. Klett-Mingo, S. Ares-Carrasco et al., "Eplerenone attenuated cardiac steatosis, apoptosis and diastolic dys- 
function in experimental type-II diabetes," Cardiovascular Diabetology, vol. 12, no. 1, article 172, 2013.

[10] M. Hamblin, D. B. Friedman, S. Hill, R. M. Caprioli, H. M. Smith, and M. F. Hill, "Alterations in the diabetic myocardial proteome coupled with increased myocardial oxidative stress underlies diabetic cardiomyopathy," Journal of Molecular and Cellular Cardiology, vol. 42, no. 4, pp. 884-895, 2007.

[11] F. J. Pashkow, "Oxidative stress and inflammation in heart disease: do antioxidants have a role in treatment and/or prevention?" International Journal of Inflammation, vol. 2011, Article ID 514623, 2011.

[12] D. L. Mann, "Inflammatory mediators and the failing heart: past, present, and the foreseeable future," Circulation Research, vol. 91, no. 11, pp. 988-998, 2002.

[13] W. Huang and C. K. Glass, "Nuclear receptors and inflammation control: molecular mechanisms and pathophysiological relevance," Arteriosclerosis, Thrombosis, and Vascular Biology, vol. 30, no. 8, pp. 1542-1549, 2010.

[14] X.-Y. Yu, H.-M. Chen, J.-L. Liang et al., "Hyperglycemic myocardial damage is mediated by proinflammatory cytokine: macrophage migration inhibitory factor," PLoS ONE, vol. 6, no. 1, Article ID e16239, 2011.

[15] S. Ares-Carrasco, B. Picatoste, A. Benito-Martín et al., "Myocardial fibrosis and apoptosis, but not inflammation, are present in long-term experimental diabetes," American Journal of Physiology-Heart and Circulatory Physiology, vol. 297, no. 6, pp. H2109-H2119, 2009.

[16] E. Haugen, J. Chen, J. Wikström, J. Grönros, L. M. Gan, and L. X. M. Fu, "Parallel gene expressions of IL-6 and BNP during cardiac hypertrophy complicated with diastolic dysfunction in spontaneously hypertensive rats," International Journal of Cardiology, vol. 115, no. 1, pp. 24-28, 2007.

[17] T. Hamid, S. Z. Guo, J. R. Kingery, X. Xiang, B. Dawn, and S. D. Prabhu, "Cardiomyocyte NF- $\kappa \mathrm{B}$ p65 promotes adverse remodelling, apoptosis, and endoplasmic reticulum stress in heart failure," Cardiovascular Research, vol. 89, no. 1, pp. 129-138, 2011.

[18] O. Lorenzo, B. Picatoste, S. Ares-Carrasco, E. Ramírez, J. Egido, and J. Tuñón, "Potential role of nuclear factor $\kappa \mathrm{b}$ in diabetic cardiomyopathy," Mediators of Inflammation, vol. 2011, Article ID 652097, 9 pages, 2011.

[19] O. Lorenzo, E. Ramírez, B. Picatoste, J. Egido, and J. Tuñón, "Alteration of energy substrates and ROS production in diabetic cardiomyopathy," Mediators of Inflammation, vol. 2013, Article ID 461967, 11 pages, 2013.

[20] B. Dong, D. Qi, L. Yang et al., “TLR4 regulates cardiac lipid accumulation and diabetic heart disease in the nonobese diabetic mouse model of type 1 diabetes," American Journal of Physiology-Heart and Circulatory Physiology, vol. 303, no. 6, pp. H732-H742, 2012.

[21] M. K. Mohammad, M. Morran, B. Slotterbeck et al., "Dysregulated Toll-like receptor expression and signaling in bone marrow-derived macrophages at the onset of diabetes in the non-obese diabetic mouse," International Immunology, vol. 18, no. 7, pp. 1101-1113, 2006.

[22] R. C. Coll and L. A. J. O’Neill, "New insights into the regulation of signalling by toll-like receptors and nod-like receptors," Journal of Innate Immunity, vol. 2, no. 5, pp. 406-421, 2010.

[23] M.-F. Tsan and B. Gao, "Endogenous ligands of Toll-like receptors," Journal of Leukocyte Biology, vol. 76, no. 3, pp. 514519,2004

[24] S. Frantz, R. A. Kelly, and T. Bourcier, "Role of TLR-2 in the activation of nuclear factor $\kappa \mathrm{B}$ by oxidative stress in cardiac myocytes," Journal of Biological Chemistry, vol. 276, no. 7, pp. 5197-5203, 2001.

[25] T. Kawai and S. Akira, "TLR signaling," Cell Death and Differentiation, vol. 13, no. 5, pp. 816-825, 2006.

[26] H. Methe, J.-O. Kim, S. Kofler, M. Weis, M. Nabauer, and J. Koglin, "Expansion of circulating toll-like receptor 4-positive monocytes in patients with acute coronary syndrome," Circulation, vol. 111, no. 20, pp. 2654-2661, 2005.

[27] S. Frantz, G. Ertl, and J. Bauersachs, "Toll-like receptor signaling in the ischemic heart," Frontiers in Bioscience, vol. 13, no. 15, pp. 5772-5779, 2008.

[28] M. R. Dasu, S. Devaraj, S. Park, and I. Jialal, "Increased TollLike Receptor (TLR) activation and TLR ligands in recently diagnosed type 2 diabetic subjects," Diabetes Care, vol. 33, no. 4, pp. 861-868, 2010.

[29] S. M. Reyna, S. Ghosh, P. Tantiwong et al., "Elevated toll-like receptor 4 expression and signaling in muscle from insulinresistant subjects," Diabetes, vol. 57, no. 10, pp. 2595-2602, 2008.

[30] Y. Ma, X. Zhang, H. Bao et al., “Toll-like receptor (TLR) 2 and TLR4 differentially regulate doxorubicin induced cardiomyopathy in mice," PLoS One, vol. 7, no. 7, article e40763, 2012.

[31] J. H. Boyd, S. Mathur, Y. Wang, R. M. Bateman, and K. R. Walley, "Toll-like receptor stimulation in cardiomyoctes decreases contractility and initiates an NF- $\kappa \mathrm{B}$ dependent inflammatory response," Cardiovascular Research, vol. 72, no. 3, pp. 384-393, 2006.

[32] T. Takahashi, "Toll-like receptors and myocardial contractile dysfunction," Cardiovascular Research, vol. 78, no. 1, pp. 3-4, 2008.

[33] H. Shi, M. V. Kokoeva, K. Inouye, I. Tzameli, H. Yin, and J. S. Flier, "TLR4 links innate immunity and fatty acid-induced insulin resistance," Journal of Clinical Investigation, vol. 116, no. 11, pp. 3015-3025, 2006.

[34] A. Schaeffler, P. Gross, R. Buettner et al., "Fatty acid-induced induction of Toll-like receptor-4/nuclear factor- $\kappa \mathrm{B}$ pathway in adipocytes links nutritional signalling with innate immunity," Immunology, vol. 126, no. 2, pp. 233-245, 2009.

[35] M. B. Fessler, L. L. Rudel, and J. M. Brown, "Toll-like receptor signaling links dietary fatty acids to the metabolic syndrome," Current Opinion in Lipidology, vol. 20, no. 5, pp. 379-385, 2009.

[36] Y. Qiao, P. Wang, J. Qi, L. Zhang, and C. Gao, “TLR-induced NF- $\kappa \mathrm{B}$ activation regulates NLRP3 expression in murine macrophages," FEBS Letters, vol. 586, no. 7, pp. 1022-1026, 2012.

[37] H. J. Ko, Z. Zhang, D. Y. Jung et al., "Nutrient stress activates inflammation and reduces glucose metabolism by suppressing AMP-activated protein kinase in the heart," Diabetes, vol. 58, no. 11, pp. 2536-2546, 2009.

[38] M. R. Dasu, S. Ramirez, and R. R. Isseroff, “Toll-like receptors and diabetes: a therapeutic perspective," Clinical Science, vol. 122, no. 5, pp. 203-214, 2012.

[39] Y. Zhang, T. Peng, H. Zhu et al., "Prevention of hyperglycemiainduced myocardial apoptosis by gene silencing of Toll-like receptor-4," Journal of Translational Medicine, vol. 8, article 133, 2010.

[40] M. J. Kolek, J. F. Carlquist, J. B. Muhlestein et al., “Toll-like receptor 4 gene Asp299Gly polymorphism is associated with reductions in vascular inflammation, angiographic coronary artery disease, and clinical diabetes," American Heart Journal, vol. 148, no. 6, pp. 1034-1040, 2004.

[41] A. Riad, H. Meyer zu Schwabedissen, K. Weitmann et al., "Variants of Toll-like receptor 4 predict cardiac recovery in patients 
with dilated cardiomyopathy," The Journal of Biological Chemistry, vol. 287, no. 32, pp. 27236-27243, 2012.

[42] M. R. Dasu, S. Devaraj, L. Zhao, D. H. Hwang, and I. Jialal, "High glucose induces toll-like receptor expression in human monocytes Mechanism of activation," Diabetes, vol. 57, no. 11, pp. 3090-3098, 2008.

[43] M. A. G. Ururahy, M. B. Loureiro, F. P. Freire-Neto et al., "Increased TLR2 expression in patients with type 1 diabetes: evidenced risk of microalbuminuria," Pediatric Diabetes, vol. 13, no. 2, pp. 147-154, 2012.

[44] K. Schroder, R. Zhou, and J. Tschopp, “The NLRP3 inflammasome: a sensor for metabolic danger?” Science, vol. 327, no. 5963, pp. 296-300, 2010.

[45] B. Vandanmagsar, Y.-H. Youm, A. Ravussin et al., "The NLRP3 inflammasome instigates obesity-induced inflammation and insulin resistance," Nature Medicine, vol. 17, no. 2, pp. 179-189, 2011.

[46] K. Hirao, H. Yumoto, K. Takahashi, K. Mukai, T. Nakanishi, and T. Matsuo, "Roles of TLR2, TLR4, NOD2, and NOD1 in pulp fibroblasts," Journal of Dental Research, vol. 88, no. 8, pp. 762767, 2009.

[47] J. A. Kummer, R. Broekhuizen, H. Everett et al., "Inflammasome components NALP 1 and 3 show distinct but separate expression profiles in human tissues suggesting a site-specific role in the inflammatory response," Journal of Histochemistry and Cytochemistry, vol. 55, no. 5, pp. 443-452, 2007.

[48] N. A. Bracey, P. L. Beck, D. A. Muruve et al., "The Nlrp3 inflammasome promotes myocardial dysfunction in structural cardiomyopathy through interleukin-lbeta," in Experimental Physiology, pp. 462-472, 2013.

[49] M. Coggins and A. Rosenzweig, "The fire within: cardiac inflammatory signaling in health and disease," Circulation Research, vol. 110, no. 1, pp. 116-125, 2012.

[50] C. Jin and R. A. Flavell, "Innate sensors of pathogen and stress: linking inflammation to obesity," Journal of Allergy and Clinical Immunology, vol. 132, no. 2, pp. 287-294, 2013.

[51] H. Wen, J. P.-Y. Ting, and L. A. J. O’Neill, “A role for the NLRP3 inflammasome in metabolic diseases-did Warburg miss inflammation?" Nature Immunology, vol. 13, no. 4, pp. 352357, 2012.

[52] A. M. K. Choi and K. Nakahira, "Dampening insulin signaling by an NLRP3 "meta-flammasome",' Nature Immunology, vol. 12, no. 5, pp. 379-380, 2011.

[53] E. Latz, T. S. Xiao, and A. Stutz, "Activation and regulation of the inflammasomes," Nature Reviews Immunology, vol. 13, no. 6, pp. 397-411, 2013.

[54] F. G. Bauernfeind, G. Horvath, A. Stutz et al., "Cutting edge: NF- $\kappa \mathrm{B}$ activating pattern recognition and cytokine receptors license NLRP3 inflammasome activation by regulating NLRP3 expression," Journal of Immunology, vol. 183, no. 2, pp. 787-791, 2009.

[55] C. Juliana, T. Fernandes-Alnemri, S. Kang et al., "Non-transcriptional priming and deubiquitination regulate NLRP3 inflammasome activation," The Journal of Biological Chemistry, vol. 287, no. 43, pp. 36617-36622, 2012.

[56] K. Shimada, T. R. Crother, J. Karlin et al., "Oxidized mitochondrial DNA activates the NLRP3 inflammasome during apoptosis," Immunity, vol. 36, no. 3, pp. 401-414, 2012.

[57] R. Zhou, A. Tardivel, B. Thorens, I. Choi, and J. Tschopp, "Thioredoxin-interacting protein links oxidative stress to inflammasome activation," Nature Immunology, vol. 11, no. 2, pp. 136-140, 2010.
[58] F. Bauernfeind, A. Rieger, F. A. Schildberg et al., "NLRP3 inflammasome activity is negatively controlled by miR-223," The Journal of Immunology, vol. 189, no. 8, pp. 4175-4181, 2012.

[59] C. J. Zuurbier, W. M. Jong, O. Eerbeek et al., "Deletion of the innate immune NLRP3 receptor abolishes cardiac ischemic preconditioning and is associated with decreased Il-6/STAT3 signaling," PLoS One, vol. 7, no. 7, article e40643, 2012.

[60] C. Hermansson, A. Lundqvist, C. Wasslavik et al., "Reduced expression of NLRP3 and MEFV in human ischemic heart tissue," Biochemical and Biophysical Research Communications, vol. 430, no. 1, pp. 425-428, 2013.

[61] S. Merkle, S. Frantz, M. P. Schön et al., "A role for caspase-1 in heart failure," Circulation Research, vol. 100, no. 5, pp. 645-653, 2007.

[62] D. Verma, M. Lerm, R. B. Julinder, P. Eriksson, P. Söderkvist, and E. Särndahl, "Gene polymorphisms in the NALP3 inflammasome are associated with interleukin-1 production and severe inflammation relation to common inflammatory diseases?" Arthritis and Rheumatism, vol. 58, no. 3, pp. 888-894, 2008.

[63] D. Verma, E. Särndahl, H. Andersson et al., “The Q705K polymorphism in NLRP3 is a gain-of-function alteration leading to excessive interleukin-1 $\beta$ and IL-18 production," PLOS ONE, vol. 7, no. 4, artile e34977, 2012.

[64] A. Dehghan, J. Dupuis, M. Barbalic et al., "Meta-analysis of genome-wide association studies in $>80000$ subjects identifies multiple loci for C-reactive protein levels," Circulation, vol. 123, no. 7, pp. 731-738, 2011.

[65] M. Kawaguchi, M. Takahashi, T. Hata et al., "Inflammasome activation of cardiac fibroblasts is essential for myocardial ischemia/reperfusion injury," Circulation, vol. 123, no. 6, pp. 594-604, 2011.

[66] H. Wen, D. Gris, Y. Lei et al., "Fatty acid-induced NLRP3-ASC inflammasome activation interferes with insulin signaling," Nature Immunology, vol. 12, no. 5, pp. 408-415, 2011.

[67] E. K. Grishman, P. C. White, and R. C. Savani, “Toll-like receptors, the NLRP3 inflammasome, and interleukin-lbeta in the development and progression of type 1 diabetes," Pediatric Research, vol. 71, no. 6, pp. 626-632, 2012.

[68] W. Wahli and L. Michalik, "PPARs at the crossroads of lipid signaling and inflammation," Trends in Endocrinology \& Metabolism, vol. 23, no. 7, pp. 351-363, 2012.

[69] E. M. Burkart, N. Sambandam, X. Han et al., "Nuclear receptors $\operatorname{PPAR} \beta / \delta$ and PPAR $\alpha$ direct distinct metabolic regulatory programs in the mouse heart," Journal of Clinical Investigation, vol. 117, no. 12, pp. 3930-3939, 2007.

[70] J. J. Wright, J. Kim, J. Buchanan et al., "Mechanisms for increased myocardial fatty acid utilization following short-term high-fat feeding," Cardiovascular Research, vol. 82, no. 2, pp. 351-360, 2009.

[71] X. Palomer, D. Álvarez-Guardia, R. Rodríguez-Calvo et al., "TNF- $\alpha$ reduces PGC- $1 \alpha$ expression through NF- $\kappa$ B and p38 MAPK leading to increased glucose oxidation in a human cardiac cell model," Cardiovascular Research, vol. 81, no. 4, pp. 703-712, 2009.

[72] I. Karakikes, M. Kim, L. Hadri et al., "Gene remodeling in type 2 diabetic cardiomyopathy and its phenotypic rescue with SERCA2a," PloS one, vol. 4, no. 7, article e6474, 2009.

[73] A. M. Quintela, R. Jimenez, M. Gomez-Guzman et al., "Activation of peroxisome proliferator-activated receptor-b/-d (PPARb/d) prevents endothelial dysfunction in type 1 diabetic rats," Free Radical Biology \& Medicine, vol. 53, pp. 730-741, 2012. 
[74] M. Collino, E. Benetti, M. Rogazzo et al., "Reversal of the deleterious effects of chronic dietary HFCS- 55 intake by PPARdelta agonism correlates with impaired NLRP3 inflammasome activation," Biochemical Pharmacology, vol. 85, no. 2, pp. 257$264,2013$.

[75] M. R. Dasu, S. Park, S. Devaraj, and I. Jialal, "Pioglitazone inhibits toll-like receptor expression and activity in human monocytes and db/db mice," Endocrinology, vol. 150, no. 8, pp. 3457-3464, 2009.

[76] C. B. Li, X. X. Li, Y. G. Chen et al., "Effects and mechanisms of PPARalpha activator fenofibrate on myocardial remodelling in hypertension," Journal of Cellular and Molecular Medicine, vol. 13, no. 11-12, pp. 4444-4452, 2009.

[77] D. Álvarez-Guardia, X. Palomer, T. Coll et al., "PPAR $\beta / \delta$ activation blocks lipid-induced inflammatory pathways in mouse heart and human cardiac cells," Biochimica et Biophysica Acta, vol. 1811, no. 2, pp. 59-67, 2011.

[78] R. Genolet, W. Wahli, and L. Michalik, "PPARs as drug targets to modulate inflammatory responses?" Current Drug Targets, vol. 3, no. 4, pp. 361-375, 2004.

[79] N. E. Buroker, J. Barboza, and J.-Y. Huang, "The $\mathrm{I} \kappa \mathrm{B} \alpha$ gene is a peroxisome proliferator-activated receptor cardiac target gene," FEBS Journal, vol. 276, no. 12, pp. 3247-3255, 2009.

[80] A. Shimamoto, A. J. Chong, M. Yada et al., "Inhibition of tolllike receptor 4 with eritoran attenuates myocardial ischemiareperfusion injury," Circulation, vol. 114, no. 1, pp. I270-I274, 2006.

[81] R. Rodríguez-Calvo, L. Serrano, T. Coll et al., "Activation of peroxisome proliferator-activated receptor $\beta / \delta$ inhibits lipopolysaccharide-induced cytokine production in adipocytes by lowering nuclear factor- $\kappa \mathrm{B}$ activity via extracellular signalrelated kinase 1/2," Diabetes, vol. 57, no. 8, pp. 2149-2157, 2008.

[82] M. J. Holness, S. Samsuddin, and M. C. Sugden, "The role of PPARs in modulating cardiac metabolism in diabetes," Pharmacological Research, vol. 60, no. 3, pp. 185-194, 2009.

[83] F. Zandbergen and J. Plutzky, "PPAR $\alpha$ in atherosclerosis and inflammation," Biochimica et Biophysica Acta, vol. 1771, no. 8, pp. 972-982, 2007.

[84] S. L. Kempster, G. Belteki, A. J. Forhead et al., "Developmental control of the Nlrp6 inflammasome and a substrate, IL-18, in mammalian intestine," American Journal of PhysiologyGastrointestinal and Liver Physiology, vol. 300, no. 2, pp. G253G263, 2011.

[85] G. S. Lee, N. Subramanian, A. I. Kim et al., “The calcium-sensing receptor regulates the NLRP3 inflammasome through $\mathrm{Ca} 2+$ and cAMP," Nature, vol. 492, no. 7427, pp. 123-127, 2012.

[86] M. Rossol, M. Pierer, N. Raulien et al., "Extracellular Ca2+ is a danger signal activating the NLRP3 inflammasome through G protein-coupled calcium sensing receptors," Nature Communications, vol. 3, p. 1329, 2012.

[87] Y. Qu, S. Misaghi, A. Izrael-Tomasevic et al., "Phosphorylation of NLRC4 is critical for inflammasome activation," Nature, vol. 490, no. 7421, pp. 539-542, 2012.

[88] M. E. Kotas, M. C. Gorecki, and M. P. Gillum, "Sirtuin-1 is a nutrient-dependent modulator of inflammation," Adipocyte, vol. 2, no. 2, pp. 113-118, 2013.

[89] M. Tanno, A. Kuno, Y. Horio et al., "Emerging beneficial roles of sirtuins in heart failure," Basic Research in Cardiology, vol. 107, no. 4, p. 273, 2012.
[90] A. Kauppinen, T. Suuronen, J. Ojala et al., "Antagonistic crosstalk between NF-kappaB and SIRT1 in the regulation of inflammation and metabolic disorders," Cell Signal, vol. 25, no. 10, pp. 1939-1948, 2013.

[91] T. Yoshizaki, S. Schenk, T. Imamura et al., "SIRT1 inhibits inflammatory pathways in macrophages and modulates insulin sensitivity," American Journal of Physiology - Endocrinology and Metabolism, vol. 298, no. 3, pp. E419-E428, 2010.

[92] P. T. Pfluger, D. Herranz, S. Velasco-Miguel, M. Serrano, and M. H. Tschöp, "Sirtl protects against high-fat diet-induced metabolic damage," Proceedings of the National Academy of Sciences of the United States of America, vol. 105, no. 28, pp. 9793-9798, 2008.

[93] R. R. Alcendor, S. Gao, P. Zhai et al., "Sirtl regulates aging and resistance to oxidative stress in the heart," Circulation Research, vol. 100, no. 10, pp. 1512-1521, 2007.

[94] A. Planavila, R. Iglesias, M. Giralt, and F. Villarroya, "Sirtl acts in association with PPAR $\alpha$ to protect the heart from hypertrophy, metabolic dysregulation, and inflammation," Cardiovascular Research, vol. 90, no. 2, pp. 276-284, 2011.

[95] F. Yeung, J. E. Hoberg, C. S. Ramsey et al., "Modulation of NF- $\kappa \mathrm{B}$-dependent transcription and cell survival by the SIRT1 deacetylase," EMBO Journal, vol. 23, no. 12, pp. 2369-2380, 2004.

[96] T. F. Liu, B. K. Yoza, M. El Gazzar, V. T. Vachharajani, and C. E. McCall, "NAD+-dependent SIRT1 deacetylase participates in epigenetic reprogramming during endotoxin tolerance," Journal of Biological Chemistry, vol. 286, no. 11, pp. 9856-9864, 2011.

[97] H. Zhu, Y. Yang, Y. Wang, J. Li, P. W. Schiller, and T. Peng, "MicroRNA-195 promotes palmitate-induced apoptosis in cardiomyocytes by down-regulating Sirtl," Cardiovascular Research, vol. 92, no. 1, pp. 75-84, 2011.

[98] F. Arslan, M. B. Smeets, L. A. J. O’Neill et al., "Myocardial ischemia/reperfusion injury is mediated by leukocytic toll-like receptor- 2 and reduced by systemic administration of a novel anti-toll-like receptor-2 antibody," Circulation, vol. 121, no. 1, pp. 80-90, 2010.

[99] H. Ehrentraut, C. Weber, S. Ehrentraut et al., "The toll-like receptor 4-antagonist eritoran reduces murine cardiac hypertrophy," European Journal of Heart Failure, vol. 13, no. 6, pp. 602610, 2011.

[100] R. C. Barber, D. L. Maass, D. J. White, L.-Y. E. Chang, and J. W. Horton, "Molecular or pharmacologic inhibition of the CD14 signaling pathway protects against burn-related myocardial inflammation and dysfunction," Shock, vol. 30, no. 6, pp. 705$713,2008$.

[101] W. Piao, S. N. Vogel, and V. Y. Toshchakov, "Inhibition of TLR4 signaling by TRAM-derived decoy peptides in vitro and in vivo," The Journal of Immunology, vol. 190, no. 5, pp. 2263-2272, 2013.

[102] N. Matsunaga, N. Tsuchimori, T. Matsumoto, and M. Ii, “TAK242 (resatorvid), a small-molecule inhibitor of Toll-like receptor (TLR) 4 signaling, binds selectively to TLR4 and interferes with interactions between TLR4 and its adaptor molecules," Molecular Pharmacology, vol. 79, no. 1, pp. 34-41, 2011.

[103] P. Chansrichavala, U. Chantharaksri, P. Sritara, and S. C. Chaiyaroj, "Atorvastatin attenuates TLR4-mediated NF- $\kappa$ B activation in a MyD88-dependent pathway," Asian Pacific Journal of Allergy and Immunology, vol. 27, no. 1, pp. 49-57, 2009.

[104] G. Földes, S. von Haehling, D. O. Okonko, E. A. Jankowska, P. A. Poole-Wilson, and S. D. Anker, "Fluvastatin reduces increased 
blood monocyte Toll-like receptor 4 expression in whole blood from patients with chronic heart failure," International Journal of Cardiology, vol. 124, no. 1, pp. 80-85, 2008.

[105] J. Yang, H. Jiang, J. Yang et al., "Valsartan preconditioning protects against myocardial ischemia-reperfusion injury through TLR4/NF- $\kappa \mathrm{B}$ signaling pathway," Molecular and Cellular Biochemistry, vol. 330, no. 1-2, pp. 39-46, 2009.

[106] H. L. Wen, Z. S. Liang, R. Zhang et al., "Anti-inflammatory effects of triptolide improve left ventricular function in a rat model of diabetic cardiomyopathy," Cardiovascular Diabetology, vol. 12, p. 50, 2013.

[107] D. Westermann, S. Van Linthout, S. Dhayat et al., "Cardioprotective and anti-inflammatory effects of interleukin converting enzyme inhibition in experimental diabetic cardiomyopathy," Diabetes, vol. 56, no. 7, pp. 1834-1841, 2007.

[108] D. Y. Fann, S. Y. Lee, S. Manzanero et al., "Intravenous immunoglobulin suppresses NLRP1 and NLRP3 inflammasomemediated neuronal death in ischemic stroke," Cell Death \& Disease, vol. 4, article e790, 2013.

[109] C. M. Larsen, M. Faulenbach, A. Vaag et al., "Interleukin1-receptor antagonist in type 2 diabetes mellitus," The New England Journal of Medicine, vol. 356, no. 15, pp. 1517-1526, 2007.

[110] J. Geiler and M. F. McDermott, "Gevokizumab, an anti-IL$1 \beta \mathrm{mAb}$ for the potential treatment of type 1 and 2 diabetes, rheumatoid arthritis and cardiovascular disease," Current Opinion in Molecular Therapeutics, vol. 12, no. 6, pp. 755-769, 2010.

[111] R. Stienstra, L. A. B. Joosten, T. Koenen et al., "The inflammasome-mediated caspase-1 activation controls adipocyte differentiation and insulin sensitivity," Cell Metabolism, vol. 12, no. 6, pp. 593-605, 2010.

[112] R. J. Shaw, K. A. Lamia, D. Vasquez et al., "Medicine: The kinase LKB1 mediates glucose homeostasis in liver and therapeutic effects of metformin," Science, vol. 310, no. 5754, pp. 1642-1646, 2005.

[113] P. W. Caton, N. K. Nayuni, J. Kieswich, N. Q. Khan, M. M. Yaqoob, and R. Corder, "Metformin suppresses hepatic gluconeogenesis through induction of SIRT1 and GCN5," Journal of Endocrinology, vol. 205, no. 1, pp. 97-106, 2010.

[114] Z. Zheng, H. Chen, J. Li et al., "Sirtuin 1-mediated cellular metabolic memory of high glucose via the LKB1/AMPK/ROS pathway and therapeutic effects of metformin," Diabetes, vol. 61, no. 1, pp. 217-228, 2012.

[115] M. Lamkanfi, J. L. Mueller, A. C. Vitari et al., "Glyburide inhibits the Cryopyrin/Nalp3 inflammasome," Journal of Cell Biology, vol. 187, no. 1, pp. 61-70, 2009.

[116] T. Jourdan, G. Godlewski, R. Cinar et al., "Activation of the Nlrp3 inflammasome in infiltrating macrophages by endocannabinoids mediates beta cell loss in type 2 diabetes," Nature Medicine, vol. 19, no. 9, pp. 1132-1140, 2013.

[117] S. Ares-Carrasco, B. Picatoste, E. Camafeita et al., "Proteome changes in the myocardium of experimental chronic diabetes and hypertension: role of PPAR $\alpha$ in the associated hypertrophy," Journal of Proteomics, vol. 75, no. 6, pp. 1816-1829, 2012.

[118] R. S. Rosenson, R. S. Wright, M. Farkouh et al., "Modulating peroxisome proliferator-activated receptors for therapeutic benefit? Biology, clinical experience, and future prospects," American Heart Journal, vol. 164, no. 5, pp. 672-680, 2012.

[119] X. C. Dong, "Sirtuin biology and relevance to diabetes treatment," Diabetes Management, vol. 2, no. 3, pp. 243-257, 2012.

[120] T. I. Lee, Y. H. Kao, Y. C. Chen et al., "Peroxisome proliferatoractivated receptors modulate cardiac dysfunction in diabetic cardiomyopathy," Diabetes Research and Clinical Practice, vol. 100, no. 3, pp. 330-339, 2013.

[121] J. Xu, M. K. Racke, and P. D. Drew, "Peroxisome proliferatoractivated receptor- $\alpha$ agonist fenofibrate regulates IL-12 family cytokine expression in the CNS: relevance to multiple sclerosis," Journal of Neurochemistry, vol. 103, no. 5, pp. 1801-1810, 2007.

[122] N. N. Ta, C. A. Schuyler, Y. Li, M. F. Lopes-Virella, and Y. Huang, "DPP-4 (CD26) inhibitor alogliptin inhibits atherosclerosis in diabetic apolipoprotein E-deficient mice," Journal of Cardiovascular Pharmacology, vol. 58, no. 2, pp. 157-166, 2011.

[123] M. Daoudi, N. Hennuyer, M. G. Borland et al., "PPAR $\beta / \delta$ activation induces enteroendocrine L cell GLP-1 production," Gastroenterology, vol. 140, no. 5, pp. 1564-1574, 2011.

[124] J. C. Milne, P. D. Lambert, S. Schenk et al., "Small molecule activators of SIRT1 as therapeutics for the treatment of type 2 diabetes," Nature, vol. 450, no. 7170, pp. 712-716, 2007. 


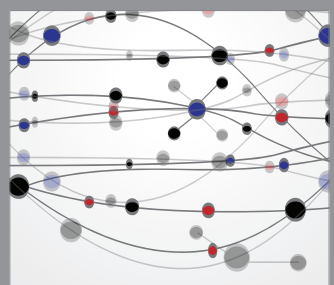

The Scientific World Journal
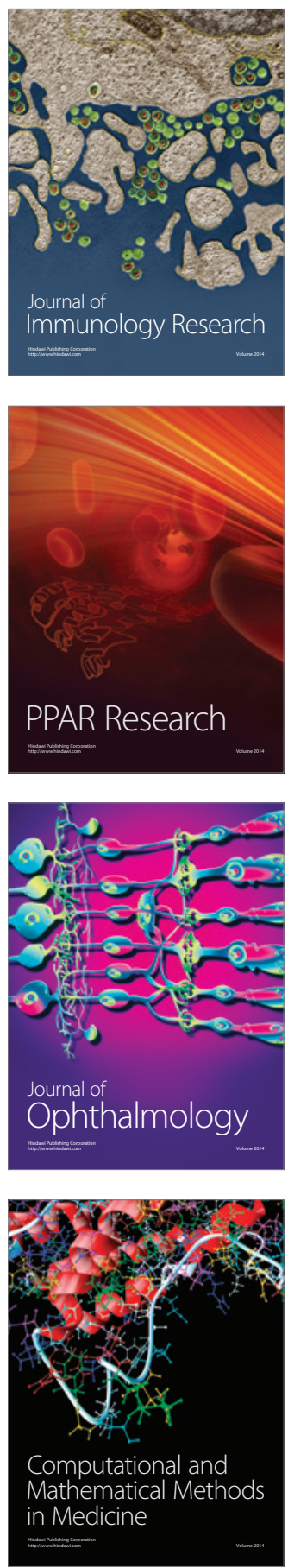

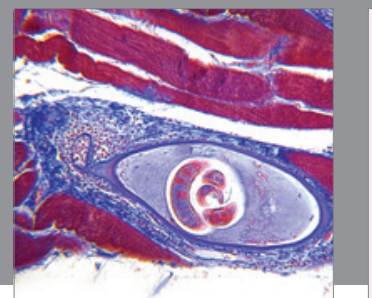

Gastroenterology

Research and Practice
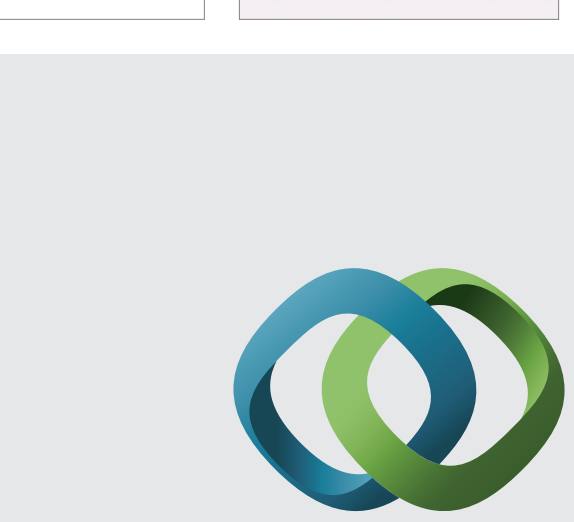

\section{Hindawi}

Submit your manuscripts at

http://www.hindawi.com
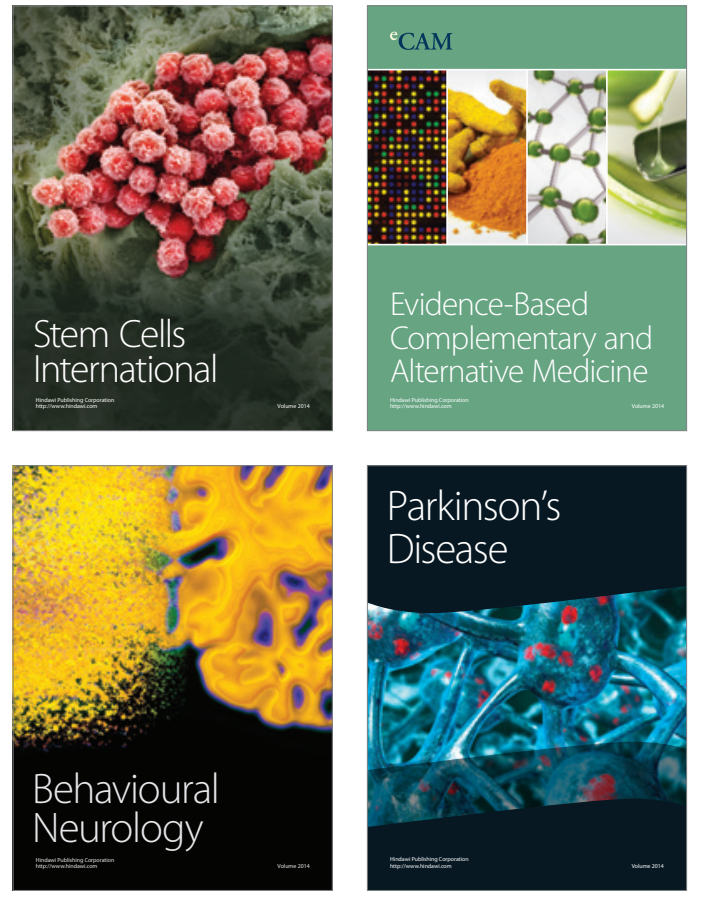
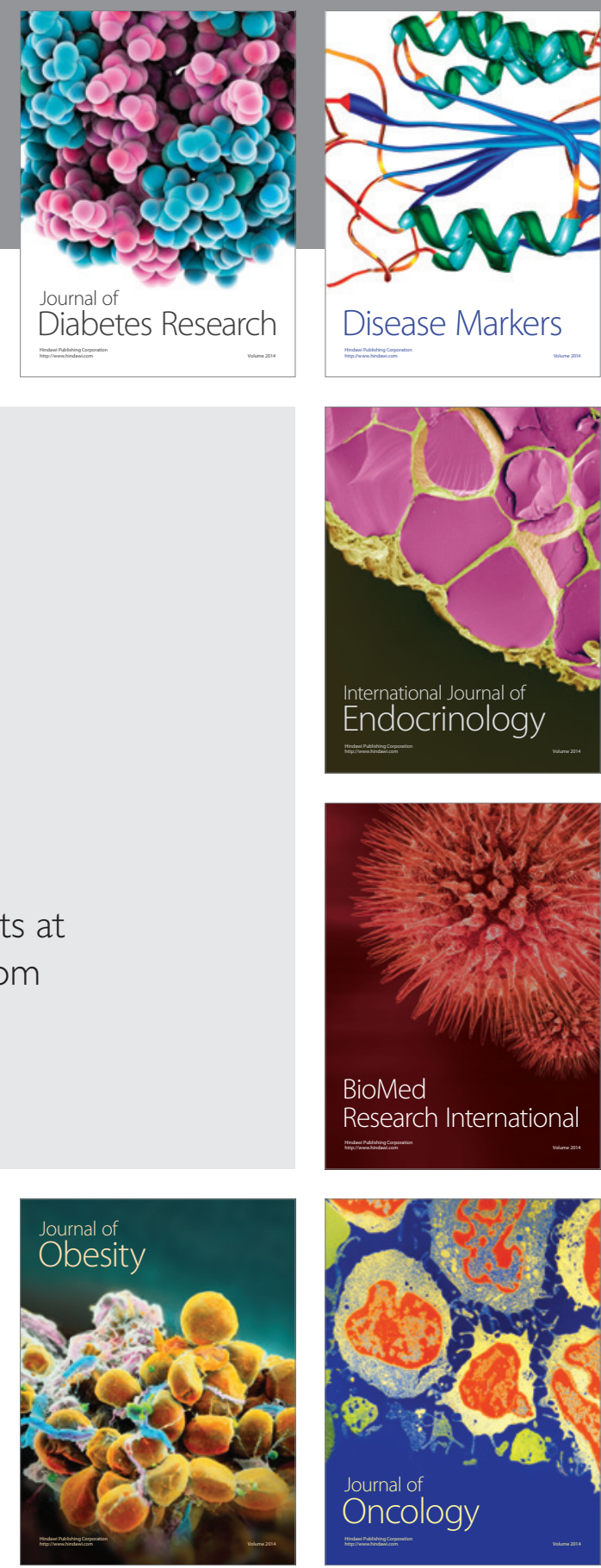

Disease Markers
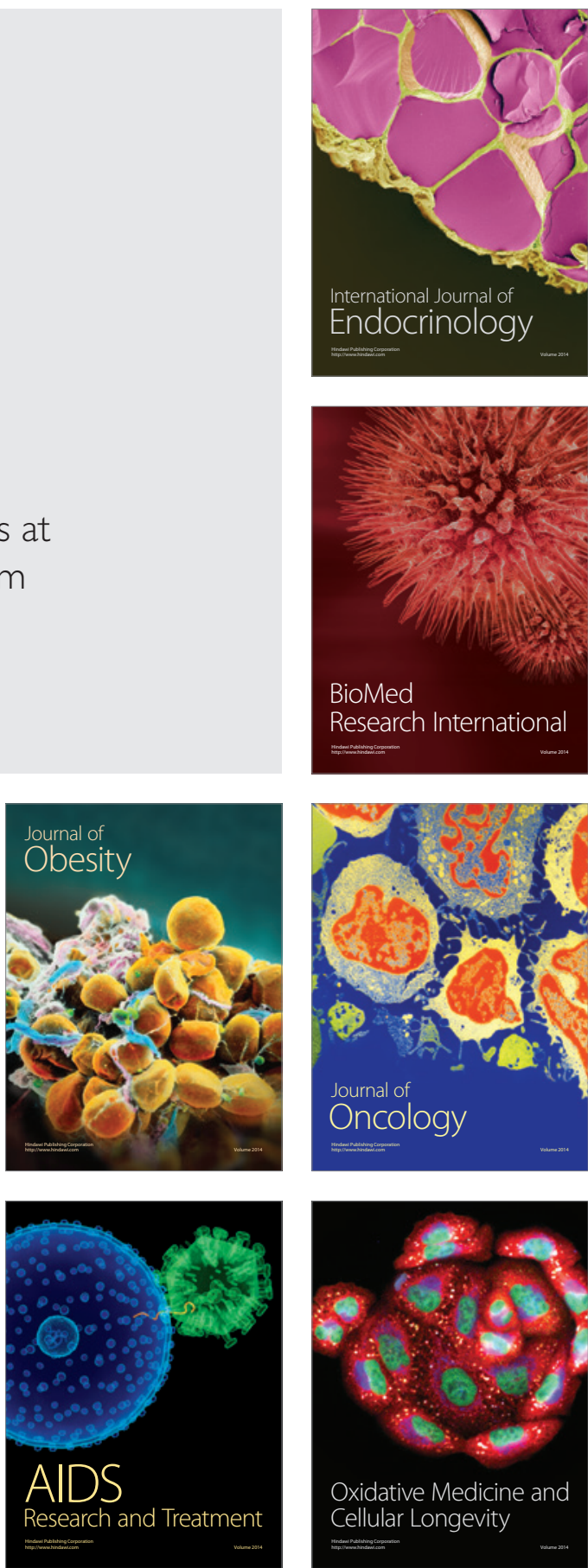